\title{
A Belgian consensus strategy to identify familial hypercholesterolaemia in the coronary care unit and its subsequent cascade screening and treatment: BEL-FaHST (The BELgium Familial Hypercholesterolaemia STrategy)
}

Olivier S. Descamps ${ }^{\text {a, }}{ }^{*}$, Olivier Van Caenegem ${ }^{\text {b }}$, Michel P. Hermans ${ }^{\mathrm{q}}$, Jean-Luc Balligand ${ }^{c}$, Christophe Beauloye ${ }^{\mathrm{b}}$, Antoine Bondue ${ }^{\mathrm{d}}$, Stéphane Carlier ${ }^{\mathrm{e}}$, Emilie Castermans ${ }^{\mathrm{f}}$, Fabien Chenot ${ }^{\mathrm{g}}$, Marc Claeys ${ }^{\mathrm{h}}$, Christophe De Block ${ }^{\mathrm{i}}$, Anne de Leener ${ }^{\mathrm{j}}$, Antoine De Meester ${ }^{\mathrm{k}}$, Fabian Demeure ${ }^{\mathrm{l}}$, Herbert De Raedt ${ }^{\mathrm{m}}$, Walter Desmet ${ }^{\mathrm{n}}$, Ivan Elegeert ${ }^{ }$, Michel Guillaume ${ }^{\mathrm{p}}$, Etienne Hoffer ${ }^{\mathrm{r}}$, Raymond Kacenelenbogen s, Patrizio Lancellotti ${ }^{t}$, Michel Langlois ${ }^{\mathrm{u}}$, Attilio Leone ${ }^{\mathrm{v}}$, Ann Mertens ${ }^{\mathrm{w}}$, Nicolas Paquot ${ }^{\mathrm{x}}$, Olivier Vanakker ${ }^{\mathrm{y}}$, Jean-Louis Vanoverschelde ${ }^{\mathrm{b}}$, Ann Verhaegen ${ }^{\mathrm{z}}$, Pieter Vermeersch ${ }^{\text {aa }}$, Caroline Wallemacq ${ }^{\mathrm{ab}}$, Ernst Rietzschel ac, On Behalf of the Belgian Atherosclerosis Society/Belgian Lipid Club (BAS/BLC), the Belgian Society of Cardiology (BSC) and the Royal Belgian Society of Laboratory Medicine (RBSLM)

a Department of Internal Medicine, Centres Hospitaliers Jolimont, Haine Saint-Paul and Department of Cardiology, UCL Cliniques Universitaires Saint-Luc, Bruxelles, Belgium

${ }^{\mathrm{b}}$ Department of Cardiology, UCL Cliniques Universitaires Saint-Luc, Bruxelles, Belgium

${ }^{\mathrm{c}}$ Department of Internal Medecine, Cliniques Universitaires Saint-Luc and Institut de Recherche Expérimentale et Clinique, UCL, Bruxelles, Belgium

d Department of Cardiology and Centre for Human Genetics, CUB Hôpital Erasme, Université Libre de Bruxelles, Brussels, Belgium

e Department of Cardiology, Centre Hospitalier Universitaire, Ambroise Paré and Mons University (UMONS), Mons, Belgium

f Department of Human Genetics, Centre Hospitalier Universitaire Sart Tilman, Liège, Belgium

${ }^{g}$ Department of Cardiology, Grand Hôpital de Charleroi, Belgium

h Department of Cardiology, University Hospital Antwerp, President of the Belgian Society of Cardiology, Belgium

i Department of Endocrinology-diabetology-metabolism, UA Antwerp University Hospital, UA Universitair Ziekenhuis Antwerpen, Belgium

j Centre de Génétique Humaine, UCL Cliniques Universitaires Saint-Luc, Bruxelles, Belgium

${ }^{\mathrm{k}}$ Department of Cardiology, Centres Hospitaliers Jolimont, Haine Saint-Paul, Belgium

${ }^{1}$ Department of Cardiology, Cliniques Universitaires de Mont-Godinne, Belgium

${ }^{\mathrm{m}}$ Department of Cardiology, Onze-Lieve-Vrouw Ziekenhuis, Aalst, Belgium

${ }^{\mathrm{n}}$ Department of Cardiovascular Medicine, Universitaire Ziekenhuizen Leuven, University Hospitals Leuven, Belgium

${ }^{\circ}$ Department of Cardiology, Algemeen Ziekenhuis, Groeninge, Kortrijk, Belgium

$\mathrm{p}$ Department of Cardiology, Centre Hospitalier Universitaire de Charleroi, Belgium

${ }^{\mathrm{q}}$ Department of Endocrinology \& Nutrition, UCL, Cliniques Universitaires Saint-Luc, Bruxelles, Belgium

${ }^{\mathrm{r}}$ Department of Cardiology, Centre Hospitalier Régional de la Citadelle, Liège, Belgium

${ }^{s}$ Department of Cardiology, CHU Saint-Pierre and President of the Working Group of Cardiovascular Readaptation and Prevention, Belgium

${ }^{t}$ GIGA Cardiovascular Sciences, Department of Cardiology, Centre Hospitalier Universitaire Sart Tilman, Liège, Belgium

" Department of laboratory Medicine, Algemeen Ziekenhuis Sint-Jan, Brugge, and National Representative of the Royal Belgian Society of Laboratory Medicine, Belgium

${ }^{\mathrm{v}}$ Department of Cardiology, Centre Hospitalier Universitaire de Tivoli La Louvière, Belgium

${ }^{\mathrm{w}}$ Department of Endocrinology, University Hospitals Leuven, Belgium

x GIGA I3, Department of Diabetes, Nutrition and Metabolic Diseases, Centre Hospitalier Universitaire Sart Tilman, Liège, Belgium

${ }^{y}$ Center for Medical Genetics, Ghent University Hospital, Ghent, Belgium

${ }^{z}$ Department of Endocrinology, Diabetology and Metabolism, Antwerp University Hospital, Antwerpen, Belgium

aa Department of laboratory Medicine, Senior Clinical Investigator of the Research Foundation-Flanders (FWO), University Hospital Leuven, The Royal Belgian Society of Laboratory Medicine, Belgium

ab Department of Diabetes, Nutrition and Metabolic Diseases, Centre Hospitalier Universitaire Sart Tilman, Liège, Belgium

${ }^{\text {ac }}$ Department of Cardiology, University Hospital Ghent and Ghent University, Belgium

\footnotetext{
* Corresponding author. Department of Internal Medicine, Centre hospitaliers Jolimont, 159, rue Ferrer, 7100 Haine Saint Paul, Belgium.

E-mail addresses: olivier.descamps@jolimont.be, olivier.descamps@uclouvain.be (O.S. Descamps).
} 
A R T I C L E I N F O

\section{Article history:}

Received 9 March 2018

Received in revised form

29 April 2018

Accepted 22 May 2018

\section{Keywords:}

Familial hypercholesterolaemia

Autosomal dominant lipoprotein disorder

Low-density lipoprotein cholesterol

Cardiovascular disease

Coronary care unit

\begin{abstract}
A B S T R A C T
Background and aims: Familial hypercholesterolaemia (FH) is an autosomal dominant lipoprotein disorder characterized by significant elevation of low-density lipoprotein cholesterol (LDL-C) and markedly increased risk of premature cardiovascular disease (CVD). Because of the very high coronary artery disease risk associated with this condition, the prevalence of FH among patients admitted for CVD outmatches many times the prevalence in the general population. Awareness of this disease is crucial for recognizing $\mathrm{FH}$ in the aftermath of a hospitalization of a patient with CVD, and also represents a unique opportunity to identify relatives of the index patient, who are unaware they have FH. This article aims to describe a feasible strategy to facilitate the detection and management of FH among patients hospitalized for CVD.

Methods: A multidisciplinary national panel of lipidologists, cardiologists, endocrinologists and cardiogeneticists developed a three-step diagnostic algorithm, each step including three key aspects of diagnosis, treatment and family care.

Results: A sequence of tasks was generated, starting with the process of suspecting FH amongst affected patients admitted for CVD, treating them to LDL-C target, finally culminating in extensive cascadescreening for FH in their family. Conceptually, the pathway is broken down into 3 phases to provide the treating physicians with a time-efficient chain of priorities.

Conclusions: We emphasize the need for optimal collaboration between the various actors, starting with a "vigilant doctor" who actively develops the capability or framework to recognize potential FH patients, continuing with an "FH specialist", and finally involving the patient himself as "FH ambassador" to approach his/her family and facilitate cascade screening and subsequent treatment of relatives.
\end{abstract}

(C) 2018 Elsevier B.V. All rights reserved.

\section{Introduction}

FH remains under-diagnosed and under-treated worldwide [1]. Up to 2013 in Belgium, only a fraction of HeFH carriers have been genetically characterized [2-8]. Many FH patients continue to suffer from early-onset cardiac complications before being diagnosed [9]. Because of the very high coronary risk associated with this disease, the prevalence of FH in patients admitted in coronary care units (CCU) outmatches more than 10 times the frequency observed in the general population (1/300) [10]. In the EUROASPIRE IV study [9], up to $8 \%$ of adults hospitalized for acute coronary syndrome (ACS) had clinical criteria compatible with potential $\mathrm{FH}$. The probability of having FH was even greater in women (11\%) and in younger patients ( $15 \%$ in those $<60$ years). Even if this is an unfortunate reality, the hospitalization of such patients for CVD is a unique opportunity to initiate the first step of FH screening. The present paper summarizes the recommendations based on current evidence and guidelines $\left({ }^{2}[11,12]\right)$ from a consensus panel composed of Belgian cardiologists, endocrinologists, lipidologists and cardiogeneticists to better organize the practice of identifying and managing $\mathrm{FH}$ patients following acute admission to CCU.

\section{Materials and methods}

OD and ER prepared a series of questions intended to achieve a consensus about a number of basic principles and to examine the feasibility and practicality of various actions to take in order to facilitate the suspicion of $\mathrm{FH}$, the confirmation of the diagnosis of $\mathrm{FH}$, the prescription of an appropriate treatment, and the initiation of family screening. A panel of national experts composed of lipidologists, cardiologists, endocrinologists and cardiogeneticists examined the current evidence and guidelines and discussed the possible organization of FH management in their local clinics. Afterwards, OD and ER provided a first draft which was then distributed ( 2 cycle of reviewing) amongst the other co-authors to receive their comments, suggestions and the final agreement on the paper content.

\section{Results}

\subsection{Basic principles}

Briefly, the management of FH implies the ability to suspect $\mathrm{FH}$ amongst admitted patients, to adequately control their LDL-C level and, in case of confirmed $\mathrm{FH}$, to propose cascade screening for $\mathrm{FH}$ in the patient's family. To reach such objectives, we developed an algorithm that splits each of the processes of diagnosis ("DIAGNOSE"), therapeutic management ("TREAT") and family screening ("FAMILY CARE") of FH into three phases named "ALERT", "CONFIRM" and "EXTEND" (Fig. 1). The idea of breaking down these processes into 3 phases is to provide doctors with a blueprint of what needs to be prioritized during each stage for the 3 processes. It involves the efforts of several stakeholders, starting with a "vigilant doctor" who suspects potential FH patients, then the expertise of an "FH specialist" and later on, the involvement of the patient him/herself as an "FH ambassador".

Since FH is a very specific and time-consuming condition to manage, a cardiologist, endocrinologist or general internist with a dedicated interest and time for FH (the "FH specialist") should be identified in each hospital, ideally assisted by a trained nurse (to educate and contact relatives for family screening) and a geneticist (to demonstrate causality of ambiguous genetic variants). Like a "diabetes clinic", a "FH clinic" should be organized to provide stateof-the-art care for FH patients and their family. The general practitioner also has a role in encouraging patients' adherence to lipidlowering drugs (LLD), and helping to perform cascade screening as extensively as possible (See Fig. 1).

The collaboration of the patient is central to approaching and motivating his/her family members and facilitating cascade screening. He/she should therefore be fully informed on the hereditary nature of his/her hypercholesterolaemia (especially when FH is confirmed) and be taught how to raise awareness in the family about the necessity to perform a cholesterol test. This may be facilitated by providing informational material on $\mathrm{FH}$ or referring to the website of the national patient's association for FH (www. belchol.be in Belgium). 


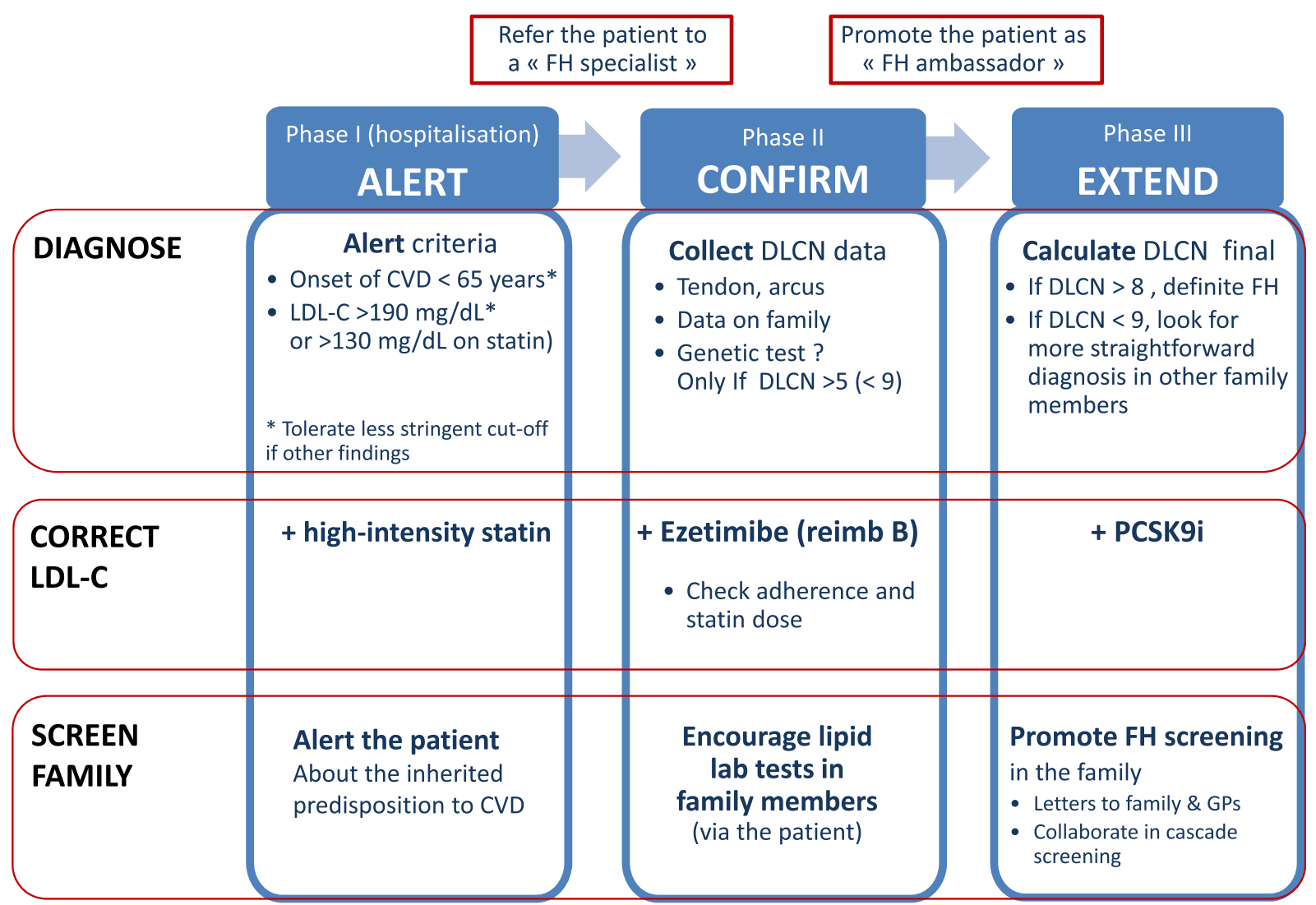

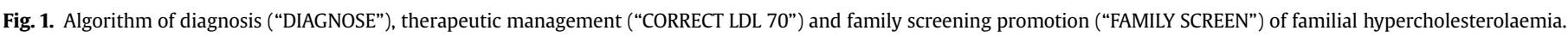

\subsection{Diagnose}

\subsubsection{Phase 1. "ALERT}

In a CCU, the first and major step of identifying a potential $\mathrm{FH}$ carrier must be integrated amongst other priorities, during a short stay and into the flow of all admitted patients. In such an acute and busy setting, it may not be appropriate to promote the use of an additional score specific to non-urgent FH diagnosis. Therefore, the panel recommends raising suspicion based on 2 simple warning signs for FH which should be checked in all patients admitted for incident CVD.

1. LDL cholesterol level (LDL-C) above $190 \mathrm{mg} / \mathrm{dl}$ without treatment, or above $130 \mathrm{mg} / \mathrm{dL}$ on LLD(s) in a blood sampling performed as soon as possible after admission (not necessarily in the fasting state); and

2. Age of onset of the acute coronary syndrome (ACS) or any other atherosclerotic disease before 65 years.

LDL-C level is little affected by the postprandial state [13] or by ACS-induced systemic inflammation, an habitual LDL-C lowering effect (10-15\%) being maximal after 4 days $[14,15]$. The cut-off of $190 \mathrm{mg} / \mathrm{dL}$ is the limit proposed by guidelines for suspecting $\mathrm{FH}(1)$. In patients currently treated with LLD, the inferior limit is expected to be around $130 \mathrm{mg} / \mathrm{dL}$ (taking into account the most commonlyused statins, simvastatin 20 or atorvastatin $10 \mathrm{mg}$, which lower LDL-C by an average 35\%), but in case of more intensive LLD, baseline LDL-C may be calculated using the correction factor specific of the ongoing LLD [16]. The panel considers a unique age cutoff for both sexes to facilitate awareness and set at an older age than usual to be more sensitive. The definition of premature family history in the DLCN is indeed far too restrictive for screening at this stage in such an environment.

These criteria, given as indication, must be nuanced using common clinical sense. For example, the age cut-off may be increased in the presence of conditions decreasing the likeliness of an earlier CV event: absence of any other CV risk factors, healthy lifestyle, longer history of LLD use. The LDL-C cut-offs may also be lowered ( $>155 \mathrm{mg} / \mathrm{dL}$ without previous LLD, and $>120 \mathrm{mg} / \mathrm{dL}$ with LLD) in the presence of strong pathognomonic signs suggesting $\mathrm{FH}$ : very early ( $<50$ years) personal CVD disease, history of premature CVD and/or hypercholesterolaemia in numerous relatives, tendon xanthomas or corneal arcus before 45 years.

In a preliminary observation of 144 admissions for ACS in one CCU (O.V.C., personal observation), it was observed that only $2 \%$ of patients met the two criteria (age cut off at 65 years plus LDLC > 190 or $130 \mathrm{mg} / \mathrm{dL}$ with LLD) whereas $6 \%$ met the "broader" criteria (age cut off at 65 plus LDL-C > 155 or $115 \mathrm{mg} / \mathrm{dL}$ with LLD). Therefore, although these criteria may not seem very specific, they already enable efficient initial selection.

In the presence of these two criteria, the patient must be referred for a visit to an $\mathrm{FH}$ specialist.

\subsubsection{Phase 2. "CONFIRM"}

The first and the subsequent visits to the "FH specialist/clinic" aim at confirming an FH diagnosis using DLCN score and/or deciding whether or not to prescribe confirmatory genetic test. This may often require more than one visit. We try here to answer some questions that are often encountered in clinical practice.

Previous history of abnormally high cholesterol levels or LLD(s).

The lifelong persistence of elevated LDL-C (especially if $>190 \mathrm{mg} / \mathrm{dL}$ in adults or $>130 \mathrm{mg} / \mathrm{dL}$ before 18 years) or early 
initiation of LLD during the course of life are indicative of $\mathrm{FH}$. In contrast, existence of previously "normal" LDL-C (around average population level) or elevated triglycerides $>200 \mathrm{mg} / \mathrm{dL}$ may lower the likelihood of monogenic $\mathrm{FH}$, and rather suggest a polygenic form of $\mathrm{FH}$ (eg. familial combined hyperlipidaemia).

3.2.2.1. Corneal arcus and tendon xanthomas. Detecting these requires some skills when examining the eyes and tendons. Tendon xanthomas are most often visible in Achilles tendons and more rarely in extensor tendons of the hands, elbows, heels and knees. Frequently, they are more palpable (feeling a nodule, or abnormal thickening) rather than visible. In case of doubt, an increase in antero-posterior thickness of Achilles tendon $(>5,8 \mathrm{~mm}$ ) demonstrated by echography is suggestive of xanthomas and may reinforce the probability of FH [17]. Unless the thickening is very high ( $>0,9 \mathrm{mmm}$ as suggested by Harada-Shiba $\mathrm{M}$ et al. [18]), this cannot replace the criterium 'tendon xanthomas" in the DLCN score. History of tendinitis is also indicative, as it occurs more frequently in $\mathrm{FH}$ patients. In interpreting these findings, it is important to exclude a previous history of tendon surgery, trauma, hyperuricemia or other conditions for tendinitis or tendon swelling.

Corneal arcus is more difficult to see on a clear (blue or green) iris, is often incomplete and/or hidden behind eyelids (it is thus important to raise eyelids, and instruct patients to look down). It is only pathognomonic of $\mathrm{FH}$ if discovered before the age of 45 years. However, the finding of a extensive or complete corneal arcus even at 50 years of age, is indicative of an earlier-onset. Xanthelasmas (sharply demarcated yellowish collections of cholesterol underneath the skin, usually on or around eyelids) are not specific of $\mathrm{FH}$.

3.2.2.2. Family data. History of hypercholesterolaemia in other members of the family (including children above 4 years) is often difficult to ascertain. The information that a relative was given a statin at a younger age may be of great interest. These points should ideally be further clarified during the forthcoming visit by asking the patient to collect more data on his/her relatives.

3.2.2.3. First DLCN assessment and genetic test prescription. On the basis of the evidence already gathered, the FH specialist can compute the DLCN score. If $>8$, it follows that the patient has FH with a high level of confidence. In this case, a genetic test is not necessary but could confirm the diagnosis as well as identify the molecular defect underlying the dyslipidemia, and may be of help in subsequent cascade screening (especially to facilitate identification of relatives with borderline cholesterol levels, especially in children). The borderline situation of DLCN between 6 and 8 often occurs in the absence of tendon xanthomas, corneal arcus $<45$ years, or LDL-C $>330 \mathrm{mg} / \mathrm{dL}$. Efforts should primarily be made to gain additional data (lipid levels in children or tendon echography, ...) that may raise the DLCN score $>8$. Otherwise, it is worth in such situation to ask for a genetic test. For a DLCN score between 3 and 5, when there are strong suggestive elements to suspect $\mathrm{FH}$, ordering a genetic analysis may also be justified. There are also situations where calculation of DLCN score is somewhat compromised and in which genetic testing may be useful: no known or living relatives (adoption; parents deceased at a younger age from non-CV causes, no contact with the family), presence of corneal arcus in a patient older than 45 years or previous history of local disease on the tendon.

We developed a table with criteria selected for helping clinicians to decide whether or not to prescribe genetic tests (Table 1). Supplementary Tables 1 and 2 summarize some of the ethical issues, benefits, indications and cautions regarding genetic testing. Genetic analysis has a significant cost, is potentially timeconsuming (obtaining results may take $2-5$ months), requires informed consent of patients on the various ethical issues, and may identify genetic variations of uncertain significance requiring additional investigations to confirm/refute causality in hypercholesterolemia. A negative genetic test does not automatically exclude FH if the DLCN score is high. In previous studies, when patients were classified on the basis of the DLCN score, 70\% of "definite" FH patients were found to carry a pathogenic variant, only $29 \%$ of "probable" $\mathrm{FH}$ and 11\% of "possible" FH patients were variant positive [19].

\subsubsection{Phase 3. "EXTEND"}

At this stage, a diagnosis of $\mathrm{FH}$ can be finalized using all confirmation data collected (including genetic test if performed). If the DLCN remains $<8$ and the genetic test is negative (Supplementary Tables 1 and 2), the clinician should not necessarily abandon the search. Sometimes, a confirmatory diagnosis may prove easier to obtain from one relative and the clinician should make every possible effort to invite some adult relatives to be examined in search of FH-specific signs (such as corneal arcus in those $<45$ years or tendon xanthomas) or children with LDL-C $>190 \mathrm{mg} / \mathrm{dL}$ (Fig. 2). Such confirmation in other family member(s) is a good argument to reinforce clinical diagnosis in the index patient.

\subsection{TREAT}

\subsubsection{Phase 1. "ALERT"}

For patients with established CHD, as considered in the present paper, initiation of LLD does not really depend upon confirmation of $\mathrm{FH}$ and must be implemented as early and as intensively as possible in order to achieve target LDL-C level $(<70 \mathrm{mg} / \mathrm{dL}$, which in $\mathrm{FH}$ patients with very elevated baseline LDL-C means a LDL-C reduction of $\geq 50 \%$ ) as per current European guidelines for patients in secondary prevention [12]. This requires prescription of high-intensity statins at the highesttolerated dose (atorvastatin $40-80 \mathrm{mg}$, rosuvastatin $20-40 \mathrm{mg}$ ) as soon as possible, preferably on first admission day for ACS. If the patient is already on low- or moderate-intensity statin, a shift to a high-intensity statin must be considered. If the patient is already on high-intensity statin, the combination of statin with ezetimibe should be considered.

\subsubsection{Phase 2. "CONFIRM"}

Successive visits to the "FH specialist" also have as objective ensuring drug compliance and adherence, titrating statins and/or adding other LLD in order to achieve LDL-C $<70 \mathrm{mg} / \mathrm{dL}$. Often, early combination with ezetimibe is required to achieve an extra $20-25 \%$ LDL-C reduction, far greater than the $6 \%$ additional reduction obtained by doubling statin dosage.

\subsubsection{Phase 3. "EXTEND"}

Even with high-intensity statins combined with ezetimibe, many FH patients still have elevated LDL-C. Therefore, at this stage, one may consider the addition of anti-PCSK9 monoclonal antibodies. Alirocumab in the ODYSSEY HIGH FH trial $[20,21]$ and evolocumab in the RUTHERFORD trial [22] have induced drastic reductions of LDL-C ( -40 to $-60 \%$ ) in FH patients on maximallytolerated statin ( \pm other LLD), allowing to achieve LDL-C target $(<70 \mathrm{mg} / \mathrm{dl}$ or $<100 \mathrm{mg} / \mathrm{dl})$ in the majority of these patients [23].

\subsection{Family care}

The process of "FAMILY CARE" includes different objectives: raising awareness of familial predisposition to CVD risk, collecting data on cholesterol values to calculate DLCN scores and cascade- 
Table 1

Probabilities that a genetic test will be positive in various situations where DLCN is $\leq 9$.

\begin{tabular}{|c|c|c|}
\hline LDL-C (mg/dL) & Other findings & Probability that genetic test will be positive \\
\hline$\geq 330$ & None (no family data) & Very high \\
\hline \multirow{3}{*}{$250-329$} & Family ( \pm personal) history but no tendon xanthomas * or corneal arcus before age 45 years ** & High \\
\hline & No family data***, with or without personal history and no other findings & High \\
\hline & No family ( \pm personal) history and no other findings & moderate \\
\hline \multirow[t]{3}{*}{$190-249$} & Family ( \pm personal) history but no tendon xanthomas * or corneal arcus before age 45 years ** & Moderate \\
\hline & No family data***, with or without personal history and no other findings & Moderate \\
\hline & No family ( \pm personal) history and no other findings & Low \\
\hline \multirow[t]{3}{*}{$150-189$} & Family ( \pm personal) history but no tendon xanthomas * or corneal arcus before age 45 years ** & Low \\
\hline & No family data***, with or without personal history and no other findings & Low \\
\hline & No family ( \pm personal) history and no other findings & Very low \\
\hline
\end{tabular}

*No tendon xanthomas or presence of tendon swelling but possibly due to other causes than FH.

**Patients is younger than 45 but has no corneal arcus or patients has corneal arcus but is older than 45 years at the moment of the examination.

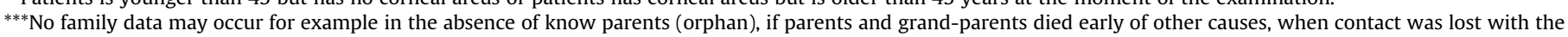
family or in case of small family.

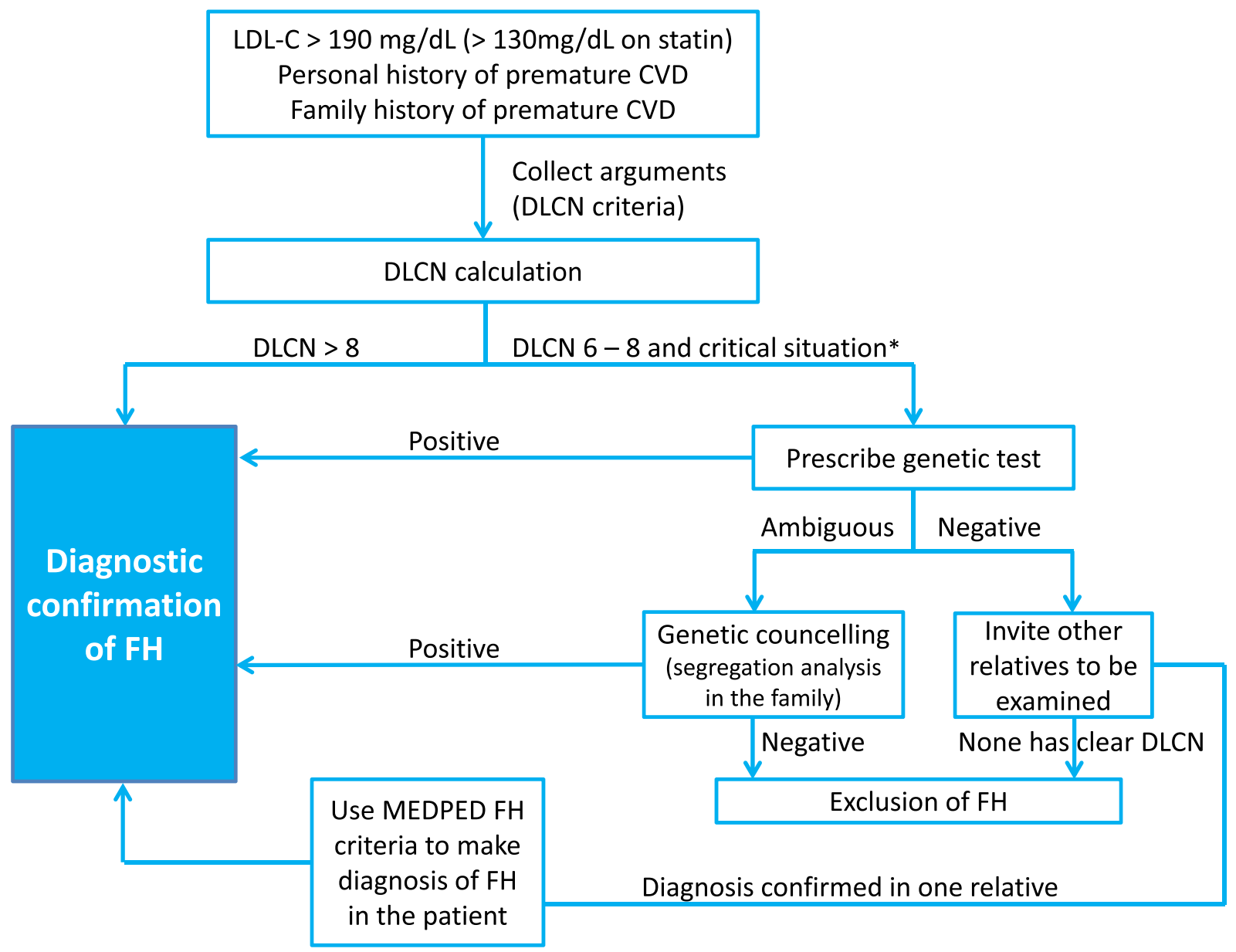

Fig. 2. Algorithm of progression in the diagnostic confirmation (or exclusion) of FH.

screening for FH. The patient's collaboration is absolutely necessary at all stages and they need to be thoroughly motivated.

\subsubsection{Phase 1."ALERT"}

When a patient suffers from CVD at an early age $(<55$ years in men and $<60$ years in women), it is usually recommended that family members be screened for lipid- and non-lipid-related CV risk factors. In this case, it is vital to notify the patient, as soon as possible, on the existence of a familial predisposition to CVD, so they may alert relatives on possible CV risk. Conversely, relatives may provide patient with additional information regarding their personal histories of hypercholesterolaemia, LLDs, and CVDs, which may help refining family data. It is however premature, at this stage, to work more actively on risk identification within the family.

\subsubsection{Phase 2. "CONFIRM"}

At this phase, still considered exploratory, the "FH specialist" will essentially try to "confirm" as much as possible the data regarding family history. At this stage, the patient may be provided with requests for laboratory testing (total cholesterol, LDL-C, HDL- 


\section{Familial Hypercholesterolaemia Recommendations for screening in adults}

Atherosclerotic disease $<65$ years

AND

LDL-C $>190 \mathrm{mg} / \mathrm{dL}$ without statin ${ }^{2}$

OR LDL-C > $130 \mathrm{mg} / \mathrm{dL}$ with high or moderate statin dose ${ }^{1}$

AND

Family history of premature* cardiovascular events

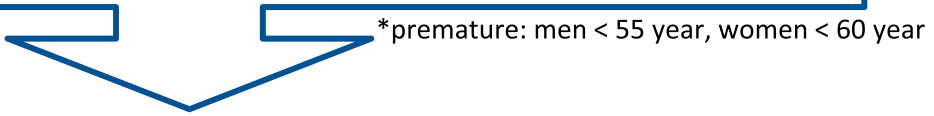

\section{Probable Familial Hypercholesterolaemia}

Refer the patient to Doctor .... to confirm the clinical diagnosis using DLCN score ${ }^{3,4}$, to achieve LDL-C target $\left(<70 \mathrm{mg} / \mathrm{dL}\right.$ ) and initiate cascade screening of the family members ${ }^{3}$

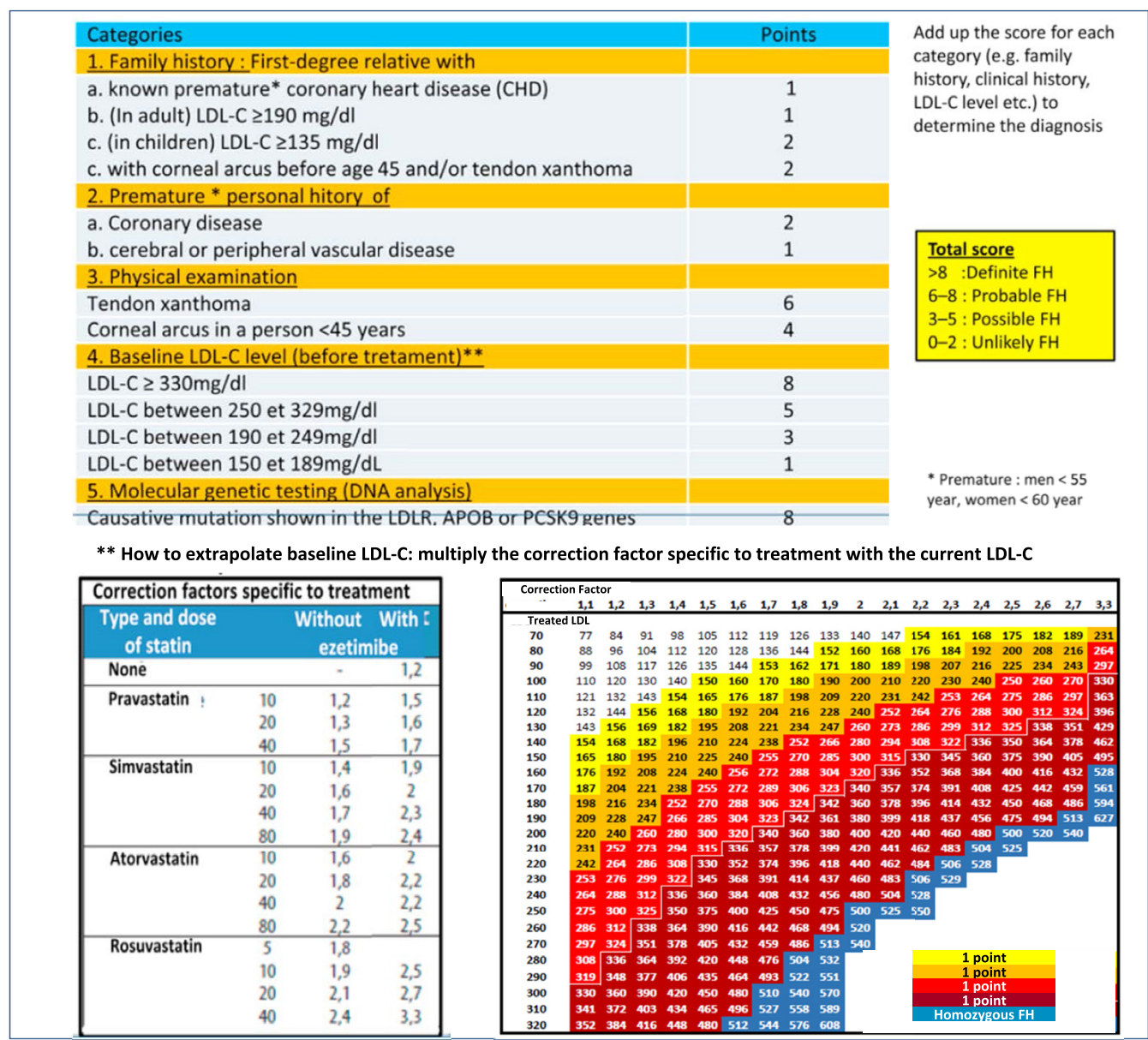

1. Schiele F et al. EHJ Acute Cardiovasc Care, p8,online 17 nov 2016; 2.EHJ Adv. Access publ. Apr 26, p12,2016;3. EHJ Adv. Access publ. Aug 27, p37,2016; 4.Pijlman QH et al. Atherosclerosis 2010; 209(1):189-194

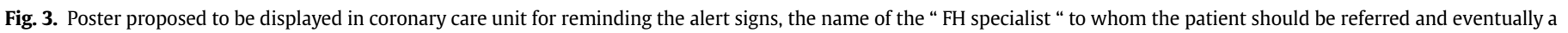
mean to calculate the baseline LDL-C if the patient is under lipid-lowering therapy (without the need of a calculator). 
C, and triglycerides) for relatives (including children) with whom the patient feels close enough to share his/her health issues. For results monitoring, the laboratory may be asked to send a copy of lab results to the relative and his/her GP.

\subsubsection{Phase 3. "EXTEND"}

Promoting hypercholesterolemia screening in the family must be done whatever the final diagnosis. However, if an FH diagnosis is well established, it must be pursued with all the more stamina, especially in children. Such family screening must be promoted through the patient ("FH ambassador"), through the patient's GP, and GPs (when identified) of relatives, and ideally with a dedicated nurse.

As first step for FH screening, the panel recommends assessment of routine lipids only, without genetic testing. Based on LDL-C, it is indeed possible to diagnose $\mathrm{FH}$ in adult relatives using the MEDPED criteria [24,25] or in children using specific diagnostic criteria [26]. The MEDPED criteria published by Roger William in $1993\left({ }^{25}\right)$ can readily be used in Belgium as the distribution of LDL-C level in general Belgian population $(131 \pm 34 \mathrm{mg} / \mathrm{dl})$ [27] is almost identical to that of the general US population $(130 \pm 31,4 \mathrm{mg} / \mathrm{dl})$. The diagnosis may be confirmed subsequently using genetic testing. Having non-elevated LDL-C does not necessarily rule out the transmission of pathogenic variants to the next generation, as incomplete penetrance of gene variants may (rarely) occur in $\mathrm{FH}$ [28]. In all cases, the $\mathrm{FH}$ specialist must be ready to respond to queries and requests for advice of screened relatives or to transfer relevant information to other colleagues if they live in a remote area.

\section{Discussion}

The aim of this consensus statement is to achieve a consistent management strategy for the identification of $\mathrm{FH}$ in patients undergoing acute CV events, for the provision of treatment and the organization of cascade screening in relatives of patients hospitalized for CVD in Belgian hospitals. Focusing on ACS, and given that each year about 10,000 ACS occur in Belgium and given that in the EUROASPIRE IV study it was estimated that $8 \%$ of adults hospitalized for ACS have clinical criteria compatible with potential undiagnosed FH [17], there is the hope that each year, there may be up to 800 new FH patients diagnosed in Belgium. More importantly, this will result in additional $\mathrm{FH}$ patients being diagnosed earlier assuming that cascade screening is adequately performed.

Currently, this strategy is being implemented in most coronary care units in Belgium. To achieve the successful implementation, a poster summarizing the strategy was created and distributed to all the coronary care units in Belgium at the end of 2017 (Fig. 3). Prior to this, face-to-face meetings with the cardiologists responsible for the CCU and their colleagues were organized to explain the rationale of the consensus strategy and the different procedures associated with it. We discussed with them the need to designate a well identified $\mathrm{FH}$ specialist, to whom all suspected patients can be referred for the validation study, we proposed to those specific centers better equipped with research coordinators to prospectively enter the data of all suspected patients as well as all other patients in order to collect more precise data on the prevalence of $\mathrm{FH}$ in the CCU and their clinical characteristics.

\section{Conflicts of interest}

Consensus Panel members (their department, their institution or personally) have received lecture honoraria, consultancy fees and/or research funding from Abbott (O.D.S., A.V., E.H.P., A.M., C.D.B., M.H.P.), Aegerion (O.D.S., A.M.), Akcea/Ionis (O.D.S., A.M.),
Amgen (O.D.S., A.V., M.L., A.L., E.H.P., I.E.C., M.G.R., A.M., S.C., E.R., J.L.B., M.H.P., C.W.), Astra Zeneca (O.D.S., A.V., M.C.J., W.D., A.L., E.H.P., A.M., A.D.M., C.B.R., C.D.B., S.C., M.H.P.), Bayer (A.B., A.D.M., C.B.R.), Boehringer Ingelheim (A.V., N.P., E.H.P., I.E.C., A.B., A.M., A.D.M., S.C., M.H.P.), Danone (O.D.S.), Daiichi Sankyo (A.D.M.), Eli Lilly (A.V., A.M., C.D.B.), Merck (O.D.S., A.V., I.E.C., M.G.R., A.M., E.R., M.H.P., C.W.), Mylan (A.V., M.H.P.), Novo Nordisk (N.P., M.H.P.), Pfizer (A.V., I.E.C.), Roche (M.L., P.V.), Sanofi-Aventis/Regeneron/ Genzyme (O.D.S., A.V., N.P., A.L., E.H.P., I.E.C., A.B., M.G.R., A.M., C.D.B., S.C., E.R., J.L.B., F.C., M.H.P., C.W.), Servier (O.D.S., E.H.P., I.E.C., C.B.R., J.L.B.), Takeda (M.H.P.), Teva (O.S.D., E.R., M.H.P.).

\section{Appendix A. Supplementary data}

Supplementary data related to this article can be found at https://doi.org/10.1016/j.atherosclerosis.2018.05.037.

\section{References}

[1] B.G. Nordestgaard, M.J. Chapman, S.E. Humphries, H.N. Ginsberg, L. Masana, O.S. Descamps, et al., European Atherosclerosis Society Consensus Panel. Familial hypercholesterolaemia is underdiagnosed and undertreated in the general population: guidance for clinicians to prevent coronary heart disease: consensus Statement of the European Atherosclerosis Society, Eur. Heart J. 34 (45) (2013) 3478-3490a.

[2] O. Descamps, J.C. Hondekijn, P. Van Acker, J.P. Deslypere, F.R. Heller, High prevalence of a novel mutation in exon 4 in the LDL receptor gene in Belgium, Clin. Genet. 51 (1997) 301-308.

[3] O.S. Descamps, J.P. Gilbeau, J.C. Hondekijn, X. Leysen, F. Van Leuven, F. Heller, Impact of genetic defects on atheroclerosis in patients suspected of familial hypercholesterolemia, Eur. J. Clin. Invest. 31 (11) (2001) 958-965.

[4] O.S. Descamps, J.B. Gilbeau, R. Luwaert, F. Heller, Impact of Genetic Defects on coronary atherosclerosis in patients suspected of familial hypercholesterolemia, Eur. J. Clin. Invest. 33 (2003) 1-9.

[5] O.S. Descamps, A. de Meester, P. Cheron, J.J. Kastelein, F.R. Heller, Clinical and preclinical myocardial ischaemia in familial hypercholesterolemia, Atherosclerosis (Supp 4) (2003) 7-8.

[6] O.S. Descamps, S. Tenoutasse, X. Stephenne, I. Gies, V. Beauloye, et al., Management of familial hypercholesterolemia in children and young adults: consensus paper developed by a panel of lipidologists, cardiologists, paediatricians, nutritionists, gastroenterologists, general practitioners and a patient organization, Atherosclerosis 218 (2) (2011) 272-280.

[7] L.F. Van Gaal, A.V. Peeters, C.E.M. De Block, R. Thiart, I.H. De Leeuw, M.J. Kotze, Low-density lipoprotein receptor gene mutation analysis and clinical correlation in Belgian hypercholesterolaemics, Mol. Cell. Probes 15 (2001) 329-336.

[8] C. Sanna, X. Stéphenne, N. Revencu, F. Smets, A. Sassolas, M. Di Filippo, O.S. Descamps, E.M. Sokal, Homozygous familial hypercholesterolemia in childhood: genotype-phenotype description, established therapies and perspectives, Atherosclerosis 247 (2016) 97-104.

[9] A.J. Vallejo-Vaz, S.R. Kondapally Seshasai, D. Cole, G.K. Hovingh, J.J. Kastelein, et al., Familial hypercholesterolaemia: a global call to arms, Atherosclerosis 243 (1) (2015) 257-259.

[10] G. De Backer, J. Besseling, J. Chapman, G.K. Hovingh, J.J. Kastelein, et al., EUROASPIRE Investigators. Prevalence and management of familial hypercholesterolaemia in coronary patients: an analysis of EUROASPIRE IV, a study of the European Society of Cardiology, Atherosclerosis 241 (1) (2015) $169-175$.

[11] J.G. Robinson, Management of familial hypercholesterolemia: a review of the recommendations from the national lipid association expert panel on familial hypercholesterolemia, J. Manag. Care Pharm. 19 (2) (2013) 139-149.

[12] A.L. Catapano, I. Graham, G. De Backer, O. Wiklund, M.J. Chapman, et al., 2016 ESC/EAS guidelines for the management of dyslipidaemias: the task force for the management of dyslipidaemias of the european society of cardiology (ESC) and european atherosclerosis society (EAS) developed with the special contribution of the european assocciation for cardiovascular prevention \& rehabilitation (EACPR), Atherosclerosis 253 (2016) 281-344.

[13] B.G. Nordestgaard, A. Langsted, S. Mora, G. Kolovou, H. Baum, et al., European atherosclerosis society (EAS) and the european federation of clinical chemistry and laboratory medicine (EFLM) joint consensus initiative. Fasting is not routinely required for determination of a lipid profile: clinical and laboratory implications including flagging at desirable concentration cutpoints-a joint consensus statement from the european atherosclerosis society and european federation of clinical chemistry and laboratory medicine, Eur. Heart J. 37 (25) (2016) 1944-1958.

[14] R. Jackson, R. Scragg, R. Marshall, et al., Changes in serum lipid concentrations during first 24 hours after myocardial infarction, BMJ 294 (1987) 1588-1589.

[15] N. Wattanasuwan, I.A. Khan, R.M. Gowda, B.C. Vasavada, T.J. Sacchi, Effect of acute myocardial infarction on cholesterol ratios, Chest 120 (4) (2001) 1196-1199. 
[16] K. Haralambos, S.D. Whatley, R. Edwards, R. Gingell, D. Townsend, et al., Clinical experience of scoring criteria for Familial Hypercholesterolaemia (FH) genetic testing in Wales, Atherosclerosis 240 (1) (2015) 190-196.

[17] O.S. Descamps, J.C. Hondekijn, F. Van Leuven, F.R. Heller, The use of Achilles tendon ultrasonography for the diagnosis of familial hypercholesterolemia, Atherosclerosis 157 (2001) 514-518.

[18] M. Harada-Shiba, H. Arai, T. Okamura, K. Yokote, S. Oikawa, A. Nohara, T. Okada, T. Ohta, H. Bujo, M. Watanabe, A. Wakatsuki, S. Yamashita, Multicenter study to determine the diagnosis criteria of heterozygous familial hypercholesterolemia in Japan, J. Atherosclerosis Thromb. 19 (11) (2012) 1019-1026.

[19] U. Kassner, M. Marion Wühle-Demuth, I. Missala, S.E. Humphries, et al., Clinical utility gene card for: hyperlipoproteinemia, TYPE II, Eur. J. Hum. Genet. 2014 (7) (November 2013) 22, https://doi.org/10.1038/ejhg.2013.271 published online 20 .

[20] J.J. Kastelein, H.N. Ginsberg, G. Langslet, G.K. Hovingh, R. Ceska, et al., ODYSSEY FH I and FH II: 78 week results with alirocumab treatment in 735 patients with heterozygous familial hypercholesterolaemia, Eur. Heart J. 36 (43) (2015) $2996-3003$.

[21] H.N. Ginsberg, D.J. Rader, F.J. Raal, J.R. Guyton, M.T. Baccara-Dinet, et al., Efficacy and safety of alirocumab in patients with heterozygous familial hypercholesterolemia and LDL-C of $160 \mathrm{mg} / \mathrm{dl}$ or higher, Cardiovasc. Drugs Ther. 30 (5) (2016) 473-483.

[22] F.J. Raal, E.A. Stein, R. Dufour, T. Turner, F. Civeira, et al., RUTHERFORD-2 Investigators. PCSK9 inhibition with evolocumab (AMG 145) in heterozygous familial hypercholesterolaemia (RUTHERFORD-2): a randomised, doubleblind, placebo-controlled trial, Lancet 385 (9965) (2015) 331-340.
[23] I. Gouni-Berthold, O.S. Descamps, U. Fraass, E. Hartfield, K. Allcott, et al. Systematic review of published Phase 3 data on anti-PCSK9 monoclonal antibodies in patients with hypercholesterolaemia, Br. J. Clin. Pharmacol. 82 (6) (2016) 1412-1443.

[24] B. Starr, S.G. Hadfield, B.A. Hutten, P.J. Lansberg, T.P. Leren, et al., Development of sensitive and specific age- and gender-specific low-density lipoprotein cholesterol cutoffs for diagnosis of first-degree relatives with familial hypercholesterolaemia in cascade testing, Clin. Chem. Lab. Med. 46 (6) (2008) 791-803.

[25] R.R. Williams, S.C. Hunt, M.C. Schumacher, R.A. Hegele, M.F. Leppert E.H. Ludwig, P.N. Hopkins, Diagnosing heterozygous familial hypercholesterolemia using new practical criteria validated by molecular genetics, Am. J. Cardiol. 72 (2) (1993) 171-176.

[26] A. Wiegman, S.S. Gidding, G.F. Watts, M.J. Chapman, H.N. Ginsberg, et al., For the European Atherosclerosis Society Consensus Panel. Familial hypercholesterolaemia in children and adolescents: gaining decades of life by optimizing detection and treatment, Eur. Heart J. 36 (36) (2015) 2425-2437.

[27] E.R. Rietzschel, M.L. De Buyzere, S. Bekaert, P. Segers, D. De Bacquer, L. Cooman, P. Van Damme, P. Cassiman, M. Langlois, P. van Oostveldt, P. Verdonck, G. De Backer, T.C. Gillebert, Asklepios Investigators. Rationale, design, methods and baseline characteristics of the Asklepios Study, Eur. J Cardiovasc. Prev. Rehabil. 14 (2) (2007) 179-191.

[28] A.V. Khera, H.H. Won, G.M. Peloso, K.S. Lawson, T.M. Bartz, et al., Diagnostic yield and clinical utility of sequencing familial hypercholesterolemia genes in patients with severe hypercholesterolemia, J. Am. Coll. Cardiol. 67 (22) (2016) 2578-2589. 